\title{
Differential genetic interactions between Sgs1, DNA-damage checkpoint components and DNA repair factors in the maintenance of chromosome stability
}

\author{
Lillian Doerfler $^{\dagger}$, Lorena Harris ${ }^{\dagger}$, Emilie Viebranz and Kristina H Schmidt ${ }^{*}$
}

\begin{abstract}
Background: Genome instability is associated with human cancers and chromosome breakage syndromes, including Bloom's syndrome, caused by inactivation of BLM helicase. Numerous mutations that lead to genome instability are known, yet how they interact genetically is poorly understood.

Results: We show that spontaneous translocations that arise by nonallelic homologous recombination in DNAdamage-checkpoint-defective yeast lacking the BLM-related Sgs1 helicase ( $\operatorname{sg} 1 \Delta$ mec3 3 ) are inhibited if cells lack Mec1/ATR kinase. Tel1/ATM, in contrast, acts as a suppressor independently of Mec3 and Sgs1. Translocations are also inhibited in cells lacking Dun1 kinase, but not in cells defective in a parallel checkpoint branch defined by Chk1 kinase. While we had previously shown that RAD51 deletion did not inhibit translocation formation, RAD59 deletion led to inhibition comparable to the rad52 $\triangle$ mutation. A candidate screen of other DNA metabolic factors identified Exo1 as a strong suppressor of chromosomal rearrangements in the sgs $1 \Delta$ mutant, becoming even more important for chromosomal stability upon MEC3 deletion. We determined that the C-terminal third of Exo1, harboring mismatch repair protein binding sites and phosphorylation sites, is dispensable for Exo1's roles in chromosomal rearrangement suppression, mutation avoidance and resistance to DNA-damaging agents.

Conclusions: Our findings suggest that translocations between related genes can form by Rad59-dependent, Rad51-independent homologous recombination, which is independently suppressed by Sgs1, Tel1, Mec3 and Exo1 but promoted by Dun 1 and the telomerase-inhibitor Mec1. We propose a model for the functional interaction between mitotic recombination and the DNA-damage checkpoint in the suppression of chromosomal rearrangements in sgs $1 \Delta$ cells.
\end{abstract}

Keywords: genome instability, translocations, Sgs1, mitotic recombination, DNA-damage checkpoint

\section{Background}

Eukaryotic cells have mechanisms at their disposal for the detection and repair of spontaneous and induced DNA lesions, thus preventing them from giving rise to potentially abnormal daughter cells. However, if these mechanisms are defective or overwhelmed by damage, deleterious chromosomal rearrangements can arise. A multitude of genes and genetic pathways for the

\footnotetext{
* Correspondence: kschmidt@usf.edu

† Contributed equally

Department of Cell Biology, Microbiology and Molecular Biology, University of South Florida, 4202 E. Fowler Avenue, Tampa, FL 33620, USA
}

maintenance of genome stability has been identified mostly using genetic screens in simple model organisms such as the yeast Saccharomyces cerevisiae. They include DNA damage checkpoints, DNA repair factors and proteins for processing of recombination substrates and intermediates [1-10]. The importance of the same mechanisms for maintaining genome stability in human cells is highlighted by the association of mutations in the human homologues of these yeast genes with chromosome breakage syndromes, which are characterized by signs of premature aging and/or cancer development. The syndromes include Nijmegen breakage syndrome
C Biomed Central

다 2011 Doerfler et al; licensee BioMed Central Ltd. This is an Open Access article distributed under the terms of the Creative Commons Attribution License (http://creativecommons.org/licenses/by/2.0), which permits unrestricted use, distribution, and reproduction in any medium, provided the original work is properly cited. 
associated with mutations in NBS1, the homologue of yeast XRS2 [11-13]; Bloom's syndrome and Werner syndrome associated with mutations in BLM and WRN, respectively, both related to yeast $S G S 1[14,15]$; and ataxia telangiectasia associated with mutations in $A T M$ [16], which is related to yeast TEL1 [17].

Yeast SGS1 encodes a 5' to 3' DNA helicase that preferentially unwinds three- and four-way junctions typical of replication and recombination intermediates and has recently been shown to collaborate with Exo1 in the long-range processing of double-strand breaks (DBSs) [18-21]. Without Sgs1, cells accumulate gross-chromosomal rearrangements (GCRs), exhibit elevated levels of mitotic recombination, have a reduced replicative lifespan and are sensitive to chemicals that alkylate DNA or slow replication forks [2,22-26]. Among DNAdamage checkpoint components, Mec1 kinase, also considered the homolog of mammalian ATR [27-29], has been identified as one of the strongest suppressors of GCRs in yeast [3,4]. Other cellular phenotypes of mec1 $\Delta$ mutants include increased sensitivity to DNA damaging agents and deficient DNA-damage checkpoint response [30], instability of stalled forks [31], accumulation of DNA breaks [32] and, in addition to these mitotic defects, deficiencies in meiotic checkpoint activation and recombination [33-35]. In contrast to Mec1, cells lacking the Tel1 checkpoint kinase, which is related to mammalian ATM $[17,36]$, are not sensitive to DNA damaging agents [17], do not accumulate GCRs above wildtype levels [3], but show telomere erosion [36]. Synergistic interactions between mec1 $\Delta$ and tel $1 \Delta$ mutations have been reported for many phenotypes, suggesting a functional relationship and redundancy between the two kinases $[3,17,37,38]$. Other checkpoint components, such as those involved in sensing DNA damage (Mec3, Rad24), appear to have only small to moderate roles in suppressing GCRs in yeast $[3,4]$. In cells lacking the Sgs1 helicase, however, Mec3 and Rad24 strongly suppress overall genome instability $[3,4]$ as well as the formation of spontaneous, recurring translocations between short identical sequences in non-allelic, but related, DNA sequences [10]. Utilizing the high susceptibility of the sgs $1 \Delta$ mec3 $\Delta$ mutant to recurring translocation formation between CAN1, LYP1 and ALP1, we have in the current study conducted a candidate screen to identify two types of DNA metabolic factors - those that are required for the formation of recurring translocations in the sgs $1 \Delta$ mec3 $\Delta$ mutant and those that act independently of Sgs1 and Mec3 to suppress translocations. For

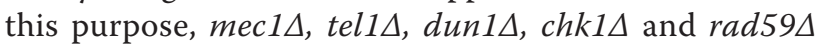

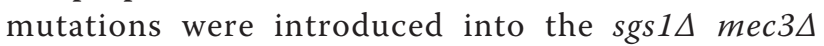
mutant and the accumulation of recurring translocations was assessed. We further determined how the lack of

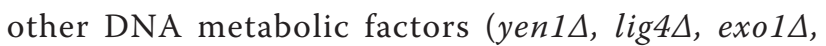

$\operatorname{rad} 1 \Delta$, pol32 $\Delta$ ) affects the accumulation of genome rearrangements, identifying a strong synergistic interaction between sgs $1 \Delta$ and exo1s. We propose an integrated model for independent, functional interactions between Sgs1, HR subpathways and various DNAdamage-checkpoint branches in the suppression of chromosomal rearrangements.

\section{Results and discussion}

Functional interaction between Sgs1 and DNA-damage checkpoint components Mec3, Mec1, Tel1, Dun1 and Chk1 in the suppression of chromosomal translocations Chromosomal translocations between short stretches of homology in nonallelic sequences that are naturally present in the yeast genome, such as the highly similar, but diverged CAN1 (on chromosome V), ALP1 and LYP1 genes (on chromosome XIV, 60-65\% identity), are normally suppressed in yeast. However, they are recurrent in sgs $1 \Delta$ mutants with certain additional DNA-metabolic

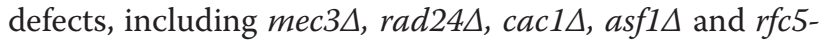
1 [10]. One of the mutants most susceptible to recurring translocations between the CAN1, LYP1 and ALP1 loci is the sgs $1 \Delta$ mec3 $\Delta$ mutant, whereas translocations are not found in the sgs $1 \Delta$ mec1 $\Delta$ mutant [10]. Here, we wanted to test whether the lack of CAN1/LYP1/ALP1 translocations in the sgs1 $\triangle$ mec1 $1 \Delta$ mutant meant that Mec1 was not a suppressor of translocations and therefore its deletion had no affect on translocation formation, or that Mec1 was actually required for the formation of viable chromosomal translocations. If the latter was true, we expected that introducing a mec1 $1 \Delta$ mutation into the highly susceptible $\operatorname{sgs} 1 \Delta$ mec $3 \Delta$ strain should inhibit the accumulation CAN1/LYP1/ALP1 translocations. Indeed, we found that while deleting $M E C 1$ led to a synergistic increase ( $\sim$-fold) in the rate of all GCR types compared to the sgs $1 \Delta$ mec3 $\Delta$ mutant $(\mathrm{P}<0.0001)$, screening of GCR clones obtained from 431 individual sgs $1 \Delta$ mec3 $\Delta$ mec1 $1 \Delta$ cultures failed to reveal a single CAN1/LYP1/ $A L P 1$ translocation, signifying a $>7$-fold decrease in the translocation rate compared to the sgs $1 \Delta$ mec $3 \Delta$ mutant (Table 1). The synergistic GCR rate increase in the sgs $1 \Delta$ mec3 $\Delta$ mec1 $\Delta$ mutant shows that Mec1 can activate its targets through Mec3-independent sensing of DNA damage. This may occur by Mec1-Ddc2 itself recognizing and binding to DNA lesions $[39,40]$ or through DNAdamage sensors other than the Mec3 clamp signaling to Mec1. The synergistic GCR rate increase in the sgs1 $\Delta$ mec3 $\triangle$ mec1 $\Delta$ mutant also indicates that the failure to form CAN1/LYP1/ALP1 translocations when MEC1 is deleted is not due to an inability to form viable GCRs, but rather suggests that DNA lesions are channeled into GCR pathways other than homology-driven translocation. Most likely, Mec1 promotes chromosomal translocations by inhibiting de novo telomere synthesis at 
Table 1 Functional interaction between Sgs1 and components of the DNA-damage checkpoint in the suppression of GCRs and translocations between CAN1, LYP 1 and ALP1 genes.

\begin{tabular}{|c|c|c|c|c|c|c|c|}
\hline \multirow[b]{2}{*}{ Relevant Genotype $^{d}$} & \multicolumn{2}{|c|}{ All GCR types ${ }^{a}$} & \multicolumn{2}{|c|}{ CAN1/LYP1/ALP1 translocations ${ }^{b}$} & \multicolumn{3}{|c|}{$\begin{array}{c}\text { Frequency of } C A N 1 / L Y P 1 / A L P 1 \\
\text { translocation types }{ }^{c}\end{array}$} \\
\hline & Rate & $95 \% \mathrm{Cl}$ & Rate & Frequency & CAN1-ALP1 & CAN1-LYP1 & CAN1-LYP1-ALP1 \\
\hline wildtype & 1.1 & $<1-6.2$ & ND & ND & ND & ND & ND \\
\hline sgs1 & 220 & $144-276$ & $<7.3$ & $0 / 30$ & $0 / 30$ & $0 / 30$ & $0 / 30$ \\
\hline rad17 & 57 & 26-74 & ND & ND & ND & ND & ND \\
\hline mec3 & 46 & $18-75$ & $<1.5$ & $0 / 30$ & $0 / 30$ & $0 / 30$ & $0 / 30$ \\
\hline mec3 rad17 & 49 & $32-64$ & ND & ND & ND & ND & ND \\
\hline sgs1 radi7 & 2515 & $903-4160$ & $<101$ & $0 / 25$ & $0 / 25$ & $0 / 25$ & $0 / 25$ \\
\hline sgst mec3 & 1297 & $1120-2030$ & 173 & $20 / 150$ & $7 / 150$ & $3 / 150$ & $7 / 150$ \\
\hline sgs 1 mec3 rad17 & 1690 & $1247-2230$ & 75 & $2 / 45$ & $1 / 45$ & $1 / 45$ & $0 / 45$ \\
\hline tel1 & 2 & ND & ND & $\mathrm{ND}$ & ND & ND & ND \\
\hline tel1 mec3 & 453 & $340-638$ & 15 & $1 / 30$ & $1 / 30$ & $0 / 30$ & $0 / 30$ \\
\hline tel1 radi7 & 129 & $73-246$ & $<8.6$ & $0 / 15$ & $0 / 15$ & $0 / 15$ & $0 / 15$ \\
\hline sgs1 tel1 & 227 & 46-418 & $N D^{b}$ & ND & ND & ND & ND \\
\hline sgs1 tel1 rad17 & 27600 & $22430-39653$ & 4600 & $6 / 36$ & $1 / 36$ & $1 / 36$ & $4 / 36$ \\
\hline sgs 1 tel1 mec3 & 57370 & $47157-76301$ & 2674 & $11 / 236$ & $0 / 236$ & $6 / 236$ & $4 / 236$ \\
\hline sgs 1 tel1 mec3 rad17 & 31960 & $23400-51800$ & ND & ND & ND & ND & ND \\
\hline mecl & 471 & 209-859 & ND & ND & ND & ND & ND \\
\hline sgst mecl & 1930 & $960-2452$ & $<10$ & $0 / 190$ & 0/190 & $0 / 190$ & $0 / 190$ \\
\hline sgst mecl mec3 & 9628 & $5870-12100$ & $<22$ & $0 / 431$ & $0 / 431$ & $0 / 431$ & $0 / 431$ \\
\hline chk1 & 42 & $25-132$ & ND & ND & ND & ND & ND \\
\hline sgs1 chk1 & 446 & $337-528$ & $<15$ & $0 / 30$ & $0 / 30$ & $0 / 30$ & $0 / 30$ \\
\hline sgs 1 chk1 mec3 & 1099 & $725-1613$ & 147 & $4 / 30$ & $1 / 30$ & $0 / 30$ & $3 / 30$ \\
\hline dun1 & 252 & 86-472 & ND & ND & ND & ND & ND \\
\hline sgsi dun1 & 1145 & 698-1910 & $<23$ & $0 / 50$ & $0 / 50$ & $0 / 50$ & $0 / 50$ \\
\hline sgs 1 dun 1 mec3 & 2800 & $2270-3570$ & $<21$ & $0 / 135$ & $0 / 135$ & $0 / 135$ & $0 / 135$ \\
\hline
\end{tabular}

${ }^{a} \mathrm{GCR}$ rate $\left(\mathrm{Can}^{r} 5-\mathrm{FOA}^{r} \times 10^{-10)} .95 \%\right.$ confidence intervals $(\mathrm{Cls})$ for median GCR rates were calculated according to Nair [80], where non-overlapping confidence intervals indicate statistically significant differences between median GCR rates. GCR rates of wildtype [81], sgs1 [82], mec3, sgs1 mec3 [60], tel1 [3] were reported previously.

${ }^{b}$ Rate of accumulating translocations between CAN1, LYP1 and/or ALP1 genes (x 10 ${ }^{-10)}$. GCR clones from sgs1, mec3, sgs1 mec3, sgs1 tel1 and sgs1 mec1 were previously screened for CAN1/LYP1/ALP1 translocations $[10,60]$.

' Types of CAN1/LYP1/ALP1 translocations were determined by sequencing. Of the 20 CAN1/LYP1/ALP1 translocations identified among 150 GCR clones from the sgs 1 mec3 mutant, 17 were identified as being either $C / A, C / L / A$ or $C / L$ translocations and 3 clones had a mixture of multiple translocations [60].

d All mutants with a mec1 deletion also contain a $s m / 1$ deletion.

chromosome breaks [1], for example by phosphorylating the telomerase-inhibitor Pif1 [41] and by phosphorylating Cdc13 and thus preventing its accumulation at DNA breaks [42]. In a haploid wildtype cell, these chromosomal translocations are expected to be rare due to restraints placed on homologous recombination events by the need for relative long regions of sequence identity. However, when the restraints on homologous recombination are relaxed and spontaneous DNA lesions are not properly detected by the DNA-damage checkpoint, as could be assumed for the sgs $1 \Delta$ mec $3 \Delta$ mutant, chromosomal translocations are promoted and occur between much shorter regions of sequence identity, such as the 541-bp segments present in CAN1, LYP1 and ALP1.

Deleting TEL1, which encodes another DNA-damage checkpoint kinase that is considered at least partially functionally redundant with Mec1, had the same effect as deleting $M E C 1$ on the accumulation of all types of GCR (Table 1), as evidenced by the 44 -fold increase in the overall GCR rate compared to the $\operatorname{sgs} 1 \Delta$ mec3 $\Delta$ mutant $\left(5.7 \times 10^{-6}\right.$ versus $\left.1.3 \times 10^{-7}, \mathrm{P}<0.0001\right)$. However, deleting TEL1 had the opposite effect on CAN1/ $L Y P 1 / A L P 1$ translocation formation (Table 1). Instead of inhibiting CAN1/LYP1/ALP1 translocations like the mec1 $1 \Delta$ mutation, the tel1 $\Delta$ mutation led to an increase ( 15-fold) in CAN1/LYP1/ALP1 translocations (Table 1). Unlike mec1 $\Delta$ mutants, mutants lacking Tel1 are impaired in their ability to maintain telomeres [36] and may thus be unable to heal DNA breaks by de novo telomere addition. Thus, in the absence of Tel1, DNA breaks may be channeled into alternative pathways for repair, such as $H R$, and more frequently give rise to CAN1/LYP1/ALP1 rearrangements under conditions that favor aberrant HR such as those in the sgs1 $1 \Delta$ 
mec3 $\Delta$ mutant. That failure to activate either Tel1 or Mec3-checkpoint pathways contributes independently to recurrent $C A N 1 / L Y P 1 / A L P 1$ translocation formation suggests that both ssDNA overhangs or gaps, thought to be sensed in a Mec3-dependent manner, and DSBs, thought to be sensed in a Tel1-dependent manner, can lead to $C A N 1 / L Y P 1 / A L P 1$ translocations and that they accumulate in unperturbed sgs $1 \Delta$ cells spontaneously. The synergistic increase in overall genome instability in the sgs $1 \Delta$ mec3 $\Delta$ tel1 $\Delta$ mutant might also indicate that in the absence of lesion binding by the Mec3 clamp some lesions are further processed and eventually detected by the Tel1-dependent pathway. For example, a stalled replication fork might eventually be processed into double-stranded ends in an attempt at fork restart by fork regression or template-switching.

Thus, both Tel1 and Mec1 act independently of Mec3 and Sgs1 to strongly suppress overall genome instability, but they affect $C A N 1 / L Y P 1 / A L P 1$ translocation formation in opposite ways. The inhibition of CAN1/LYP1/ $A L P 1$ translocations upon $M E C 1$ deletion as opposed to their increase upon TEL1 deletion can most likely be explained by their opposite effects on telomere synthesis, with Mec1 inhibiting it and Tel1 promoting it. This is also consistent with the previous report of different GCR spectra in the tel1 $\Delta$ and mec1 $\Delta$ single mutants [1]. Apart from regulating telomere maintenance factors, it is also conceivable that the DNA-damage checkpointdependent phosphorylation of homologous recombination factors, such as Rad55, Slx4 and Mus81 [43-47] contributes to differential regulation of translocation formation in the sgs $1 \Delta$ mec3 $\Delta$ mutant.

The opposing effects of Tel1 and Mec1 on CAN1/ $L Y P 1 / A L P 1$ translocation formation led us to investigate other DNA-damage checkpoint components in sgs1 1 and $\operatorname{sgs} 1 \Delta$ mec3 $\Delta$ mutants. We found that deletion of either CHK1 or DUN1 led to a synergistic increase in overall genome instability when combined with an sgs1 $\Delta$ mutation $(\mathrm{P}<0.0001)$, however only the dun1 1 mutation caused a further significant GCR rate increase in the sgs $1 \Delta$ mec $3 \Delta$ mutant $(\mathrm{P}<0.0001$, Table 1$)$ whereas the $\operatorname{chk} 1 \Delta$ mutation did not $(\mathrm{P}=0.1615$, Table 1$)$. Analysis of the GCR types revealed accumulation of CAN1/ $L Y P 1 / A L P 1$ translocations in the Chk1-deficient sgs1 mec3 $\Delta$ mutant at a similar rate as in the sgs $1 \Delta$ mec3 $\Delta$ mutant, but not in the Dun1-deficient sgs $1 \Delta$ mec3 $\Delta$ mutant (Table 1), indicating that Dun1, like Mec1, promotes translocation events between CAN1, LYP1 and ALP1 whereas Chk1 does not. This is likely due to Mec1-mediated activation of Dun1 kinase, which in turn inactivates the transcription repressor Crt1, thus allowing transcription of several DNA-damage inducible genes $[48,49]$. Chk1 kinase is also activated through Mec1 in response to DNA damage and causes a transient $\mathrm{G} 2 / \mathrm{M}$ arrest by blocking anaphase progression $[50,51]$. However, in contrast to Dun 1, Chk1 is not thought to regulate DNA repair pathways, and its deletion did not inhibit translocation formation in the sgs $1 \Delta$ mec3A mutant (Table 1). As expected, deletion of $R A D 17$, which encodes another subunit of the Mec3/ Rad17/Ddc1 checkpoint clamp, had a similar effect on CAN1/LYP1/ALP1 translocation formation in the sgs1A tel1 $\triangle$ mutant as deletion of $M E C 3$ (Table 1). The detection of a $C A N 1 / L Y P 1 / A L P 1$ translocation in two strains

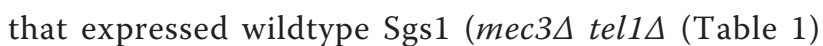
and mec3 $\Delta$ tel1 $\Delta$ rad $17 \Delta$ (not shown)) suggests that even in the presence of wildtype Sgs1 cells may accumulate $C A N 1 / L Y P 1 / A L P 1$ translocations as long as they are deficient in at least two independent suppressors of translocation formation, such as Tel1 and Mec3 identified here.

\section{Deletion of RAD59 inhibits spontaneous} interchromosomal translocations between short repeats We previously showed that translocations between CAN1, LYP1 and ALP1 in the sgs1 1 mec3A mutant are Rad52-dependent, but translocations still formed when Rad51 was absent [10]. To assess the role of other HR factors in translocation formation we deleted $R A D 59$ in the highly susceptible $\operatorname{sgs} 1 \Delta$ mec $3 \Delta$ mutant and measured the rate of accumulating all types of GCRs as well as CAN1/LYP1/ALP1 translocations. One CAN1/LYP1/ $A L P 1$ rearrangement was identified among GCR clones obtained from 158 independent cultures of the sgs $1 \triangle$ mec $3 \Delta$ rad59 $\Delta$ mutant (Table 2 ), indicating a 10 -fold reduction in the $C A N 1 / L Y P 1 / A L P 1$ translocation rate compared to the sgs $1 \Delta$ mec3 $\Delta$ mutant. Thus, similar to $\operatorname{Rad} 52, \operatorname{Rad} 59$ is required for interchromosomal translocations between short identical sequences in related genes. If Rad59 was indeed required for translocation formation, we predicted that the formation of CAN1/ $L Y P 1 / A L P 1$ translocations in the sgs $1 \Delta$ mec3A $\mathrm{rad} 51 \Delta$ mutant would also be inhibited by a rad59 $\Delta$ mutation.

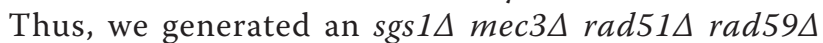
mutant and screened for CAN1/LYP1/ALP1 translocations. Among 168 independent GCR clones we identified one CAN1/LYP1/ALP1 translocation, indicative of a 28 -fold reduction of the translocation rate compared to the sgs $1 \Delta$ mec3 $\Delta$ rad51 1 mutant (Table 2). Thus translocations between CAN1, LYP1 and/or ALP1 can form through $\operatorname{Rad} 52 / \operatorname{Rad} 59$-mediated HR that does not require Rad51. Rad59 has recently also been shown to contribute to GCRs mediated by certain Ty-elements and to translocations involving short DNA sequences of limited sequence identity [6,52].

While $\operatorname{Rad} 52$ is required for all HR in yeast, some DNA breaks can be repaired by HR pathways that do not require $\operatorname{Rad} 51$, including single-strand annealing 
Table 2 Effect of homologous recombination mutations on the ability of the sgs 1 mec 3 mutant to accumulate GCRs and form rearrangements between the CAN1, LYP 1 and ALP1 genes.

\begin{tabular}{|c|c|c|c|c|}
\hline \multirow[b]{2}{*}{ Relevant genotype } & \multicolumn{2}{|c|}{$\begin{array}{l}\text { All GCR } \\
\text { types }^{a}\end{array}$} & \multicolumn{2}{|c|}{$\begin{array}{l}C A N 1 / L Y P 1 / A L P 1 \\
\text { translocations }{ }^{b}\end{array}$} \\
\hline & Rate & $95 \% \mathrm{Cl}$ & Rate & Frequency \\
\hline wildtype & 1.1 & $<1-6.2$ & ND & ND \\
\hline $\operatorname{rad} 51^{a}$ & $<8$ & $<7-15$ & ND & ND \\
\hline rad52 & 138 & $16-267$ & ND & ND \\
\hline rad59 & 24 & $13-50$ & ND & ND \\
\hline $\operatorname{sgs} 1^{a}$ & 220 & $144-276$ & $<7.3$ & $0 / 30$ \\
\hline $\operatorname{mec} 3^{a}$ & 46 & 18-75 & $<1.5$ & $0 / 30$ \\
\hline sgs1 rad59 & 126 & $107-300$ & $N D$ & $N D$ \\
\hline sgs1 rad59 rad51 & 118 & 49-154 & ND & ND \\
\hline $\operatorname{sgs} 1 \operatorname{mec}^{a}$ & 1297 & $1120-2030$ & 173 & $20 / 150$ \\
\hline $\operatorname{sgs} 1 \operatorname{mec} 3 \operatorname{rad} 51^{a}$ & 1491 & $\mathrm{ND}^{c}$ & 198 & $4 / 30$ \\
\hline $5 g 51 \operatorname{mec} 3 \operatorname{rad} 52^{a}$ & 3168 & $N D^{c}$ & $<23$ & $0 / 136$ \\
\hline sgs1 mec3 rad59 & 2476 & $1595-3187$ & 16 & $1 / 158$ \\
\hline sgs 1 mec3 rad59 rad51 & 1124 & $734-1460$ & 7 & $1 / 168$ \\
\hline
\end{tabular}

${ }^{a}$ Median rate of cells resistant to canavanine and 5-FOA $\left(\mathrm{Can}^{r} 5-\mathrm{FOA}^{r} \times 10^{-10)}\right.$. 95\% confidence intervals (Cls) for median GCR rates were calculated according to Nair [80], where non-overlapping confidence intervals indicate statistically significant differences between median GCR rates. GCR rates for wildtype [81], sgs1 [82], mec3, sgs1 mec3 [60], rad51, sgs1 mec3 rad51 and sgs 1 mec3 rad52 mutants [10] were reported previously and are included for comparison.

${ }^{b}$ Rate of accumulating translocations between CAN1, LYP1 and/or ALP1 (Can ${ }^{r}$ $5-\mathrm{FOA}^{r} \times 10^{-10)}$. GCR clones from sgs1, mec3, sgs1 mec3, sgs 1 mec3 rad51, sgs 1 mec3 rad52 were previously screened for CAN1/LYP1/ALP1 translocations $[10,60]$. ND, not determined.

'To determine $95 \% \mathrm{Cls}$ for sgs 1 mec3 rad51 and sgs 1 mec3 rad52 mutants, GCR rates were re-measured for the current study. The GCR rate for the sgs 1 mec3 rad51 mutant was $1933 \times 10^{-10}\left(95 \% \mathrm{Cls}: 601-2240 \times 10^{-10}\right)$ and the GCR rate for the sgs 1 mec3 rad52 mutant was $2220 \times 10^{-10}\left(951-3470 \times 10^{-10}\right)$. The previously reported rates fall within the $95 \% \mathrm{Cls}$ determined in the current study.

(SSA), break-induced replication (BIR) and recombination-mediated telomere-lengthening Type II [53-58]. SSA is a mechanism for the repair of a DSB between repeated DNA elements and requires $\operatorname{Rad} 59$, but not Rad51 [59]. In order for the interchromosomal CAN1/ $L Y P 1 / A L P 1$ rearrangements to arise by SSA, however, at least two DSBs would have to occur in the same cell one DSB within or downstream of CAN1 on chromosome V and one DSB near ALP1 (or LYP1) on chromosome XIV. Resection would expose the short stretches of homology shared by CAN1 and ALP1 (or LYP1) [60], allowing them to anneal, followed by removal of the nonhomologous overhangs and ligation. Rad59-dependent, Rad51-independent interchromosomal translocation between his3 fragments was recently shown after induction of HO-breaks in the two recombining chromosomes [61]. Such an interchromosomal SSA event could also produce the types of rearrangements we have observed between CAN1, LYP1 and ALP1; however, the ends of chromosomes V and XIV not engaged in the
SSA event would be left unrepaired and most likely would be lost after cell division unless the recombination event occurs in G2/M when sister-chromatids are present. Moreover, since we have shown that wildtype copies of $L Y P 1$ and $A L P 1$ are still present in recombinants with $C A N 1 / L Y P 1 / A L P 1$ rearrangements, indicative of a nonreciprocal translocation event [60], and the parts of chromosome XIV that would be lost after SSA contain essential genes, SSA is unlikely to be the main recombination mechanism that gives rise to CAN1/ LYP1/ALP1 rearrangements.

Besides SSA, BIR also matches the genetic requirements for CAN1/LYP1/ALP1 translocation formation. BIR is initiated by invasion of a duplex by a singlestranded 3'end of a one-sided DBS followed by replication to the chromosome end. Although Sgs1 has roles in recombination, specifically sister-chromatid exchange and resolution of recombination intermediates [2,9,62-64], it is not required for Rad51-independent BIR [57]. In contrast to SSA, the nonreciprocal nature of BIR events would maintain an intact copy of chromosome XIV in addition to the chromosome V/XIV translocation, suggesting that it is the more likely mechanism involved in CAN1/LYP1/ALP1 translocation. BIR has been implicated in the repair of one-sided DSBs, such as replication forks that collapsed at a single-strand break. BIR is also thought to allow telomerase-deficient cells $(t l c 1 \Delta)$, whose telomeres have shortened to a point where cells can no longer proliferate, to survive by extending what could be considered a one-sided DSB. Survivors can arise either by adding subtelomeric $Y$ ' elements in a Rad51-dependent mechanism (Type I) or by adding telomeric $\left(\mathrm{G}_{1-3} \mathrm{~T}\right)_{\mathrm{n}}$ repeats in a Rad51-independent, but Rad59-dependent mechanism (Type II) [53-55]. The differential requirement for Rad51 and Rad59 in these two pathways is thought to result from the differences in length and sequence identity of the recombination substrates for Type I and Type II [53]. The long, nearly identical $(\sim 1 \%$ variation within the same strain) $Y$ ' elements [65] are thought to be better substrates for Rad51-mediated strand invasion, whereas Rad59 is able to use the shorter stretches of homology likely to be found within the highly variable $\left(\mathrm{G}_{1-3} \mathrm{~T}\right)_{\mathrm{n}}$ repeats [53]. Besides BIR, evidence of homology-length dependency is also seen in gene conversion, with Rad59 becoming increasingly important as the length of sequence homology decreases [59]. This length-dependency may also explain our observation that CAN1/ LYP1/ALP1 rearrangements, which show short regions of homology at the breakpoints $[10,60]$, are inhibited by deletion of RAD59, but not by deletion of RAD51. Despite this differential effect on chromosome rearrangements between CAN1, LYP1 and ALP1, we observed no difference in the rate of overall genome instability 


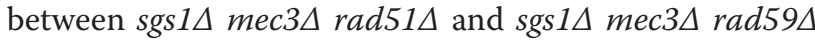
mutants $(P=0.6892$, Table 2), suggesting that the DNA lesions that give rise to viable GCRs are accessible to multiple repair pathways.

\section{Candidate screen reveals EXO1 as a strong suppressor of GCR formation in cells lacking Sgs1}

To assess the possible role of other DNA metabolic factors in the suppression or formation of GCRs in cells

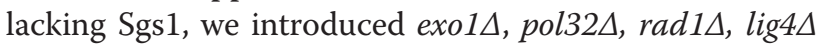
and yen $1 \Delta$ mutations into sgs $1 \Delta$ and $\operatorname{sgs} 1 \Delta$ mec3 $\Delta$ mutants. Screening of the single, double and triple mutants revealed that RAD1, POL32, LIG4 and YEN1 are not strong suppressors of GCRs in wildtype cells, or in sgs $1 \Delta$ or sgs $1 \Delta$ mec3 $\Delta$ mutants (Table 3). However, when we assessed the formation of CAN1/LYP1/ALP1 translocations in sgs $1 \Delta$ mec3 $\Delta$ mutants with pol32 $\Delta$ or $\mathrm{rad} 1 \Delta$ mutations we found that in both triple mutants CAN1/LYP1/ALP1 translocations were inhibited, revealing one CAN1/LYP1 translocation among 98

\begin{tabular}{|c|c|c|}
\hline Relevant genotype $^{a}$ & GCR rate ${ }^{b}$ & $95 \% \mathrm{Cl}^{\mathrm{c}}$ \\
\hline wildtype & 1.1 & $<1-6.2$ \\
\hline exo1 & 24 & $7-79$ \\
\hline sgs 1 & 220 & $144-276$ \\
\hline sgs 1 mec3 & 1297 & $1120-2030$ \\
\hline exol sgst & 43800 & $30400-186000$ \\
\hline exo1 mec3 & 30 & $12-39$ \\
\hline exol mec3 sgs1 & 1168498 & $549530-3251000$ \\
\hline sgst mec3 exol lig4 & 895988 & $701149-1236740$ \\
\hline lig4 & 16 & ND \\
\hline sgs7 lig4 & 80 & $35-254$ \\
\hline sgst mec3 lig4 & 1335 & $948-2140$ \\
\hline yen 1 & $<5$ & $<4-6$ \\
\hline sgs1 yen 1 & 81 & $57-265$ \\
\hline sgs 1 mec3 yen 1 & 1089 & $254-2540$ \\
\hline pol32 & 20 & $15-26$ \\
\hline sgs1 pol32 & 25 & $<24-105$ \\
\hline sgs1 mec3 pol32 & 2317 & $1800-3110$ \\
\hline rad1 & 10 & $<9-23$ \\
\hline sgst rad1 & 63 & $25-356$ \\
\hline sgs 1 mec3 rad1 & 1173 & $1020-1540$ \\
\hline
\end{tabular}

${ }^{a}$ Strains with multiple gene deletions were constructed by sporulation of the appropriate heterozygous diploids. GCR rates with $95 \%$ confidence intervals (Cls) for wildtype [81], sgs1 [82], sgs1 mec3 [60] and lig4 [1] were reported previously and are included for comparison. Spores with both sgs $1 \Delta$ and po/32 $\Delta$ mutations grew very slowly and exhibited a low viable cell count on YPD in the GCR assay.

${ }^{b}$ The rate of accumulating gross-chromosomal rearrangements (GCRs) is calculated by selecting for cells resistant to canavanine $\left(\mathrm{Can}^{r}\right)$ and 5 -fluoroorotic acid $\left(5-\mathrm{FOA}^{r}\right)$ and is expressed as $\mathrm{Can}^{r} 5-\mathrm{FOA}^{\mathrm{r}} \times 10^{-10}$ [77].

c $95 \%$ confidence intervals (Cl) for median GCR rates were calculated according to Nair [80]. independent GCR clones in the sgs $1 \Delta$ mec3A pol32 $\Delta$ mutant and none $(0 / 55)$ in the $\operatorname{sgs} 1 \Delta$ mec3 $\Delta$ rad $1 \Delta$ mutant. Pol32, a nonessential subunit of polymerase $\delta$ that promotes processivity of the polymerase, is not required for SSA, but for DNA repair processes that involve extensive DNA synthesis, such as BIR [66], consistent with BIR being a pathway for CAN1/LYP1/ALP1 translocation formation. Although Rad1, a subunit of the Rad1-Rad10 nuclease critical for the removal of nonhomologous overhangs from annealed single strands in processes such as SSA $[67,68]$, has not been shown to be required for BIR, it has been implicated in the removal of nonhomologous overhangs during GCR formation [69] and in recombination events that combine BIR and SSA processes [70,71].

Deletion of EXO1, coding for a nuclease with 5' to 3' exonuclease and flap-endonuclease activities, which has roles in mitotic and meiotic recombination as well as mutation avoidance and is thought to cooperate with Sgs1 in the processing of DSBs [19,72], induced the largest synergistic GCR rate increase we have observed to date in the sgs $1 \Delta$ mutant. While sgs $1 \Delta$ and exo1 $\Delta$ single mutants exhibited moderately increased GCR rates compared to wildtype, the GCR rate of the sgs $1 \Delta$ exol $\Delta$ mutant was several hundred-fold higher than the rates of the single mutants $(\mathrm{P}<0.0001$, Table 3$)$. This GCR rate increased another 26-fold upon deletion of $M E C 3$ $(\mathrm{P}<0.0001$, Table 3). Screening of GCRs obtained from 66 independent cultures of the sgs $1 \Delta$ mec3 $\Delta$ exo1 $1 \Delta$ mutant identified two CAN1/LYP1/ALP1 translocations, indicating a 200-fold increase in the CAN1/LYP1/ $A L P 1$ translocation rate compared to the sgs $1 \Delta$ mec3A mutant $\left(3.5 \times 10^{-6}\right.$ versus $\left.1.7 \times 10^{-8}\right)$.

Exo1 contains conserved N-terminal N- and I-nuclease domains, apparently separated by a short disordered linker, and binding sites for the mismatch repair (MMR) proteins Mlh1 and Msh2 have been located within the C-terminal half of Exo1 [72-74], which is predicted to be intrinsically disordered (Figure 1A). Four phosphorylation sites (S372, S567, S587, S692) required for the regulation of the DNA-damage response have also been located in the disordered C-terminus [75]. To determine if the $\mathrm{C}$-terminus of Exo1 plays a role in the suppression of genome instability in the sgs $1 \Delta$ mutant we constructed a set of $\mathrm{C}$-terminal deletions ranging from 100 to 400 residues (Figure 1A and $1 \mathrm{~B}$ ). We found that the C-terminal 260 residues of Exo1, making up 37\% of the protein, play no major role in suppressing the accumulation of GCRs in the sgs $1 \Delta$ mutant (Table 4). To test the possibility that the $\mathrm{C}$-terminus with its binding sites for MMR proteins might be required for Exol's role in mutation avoidance, but not for its role in suppressing GCRs, we utilized a fluctuation assay to determine the rate of accumulating canavanine resistance $\left(\mathrm{Can}^{\mathrm{r}}\right)$ 
A

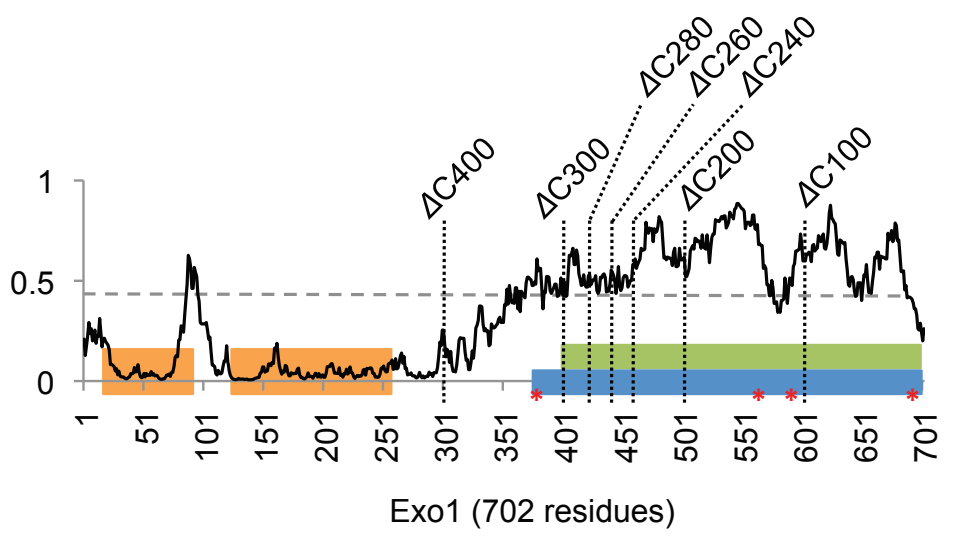

B

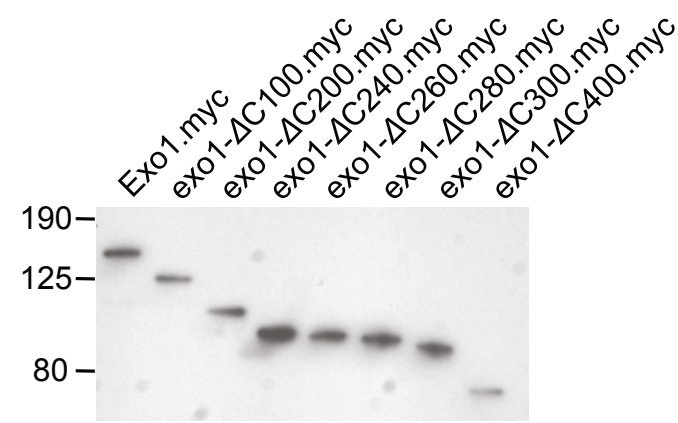

C
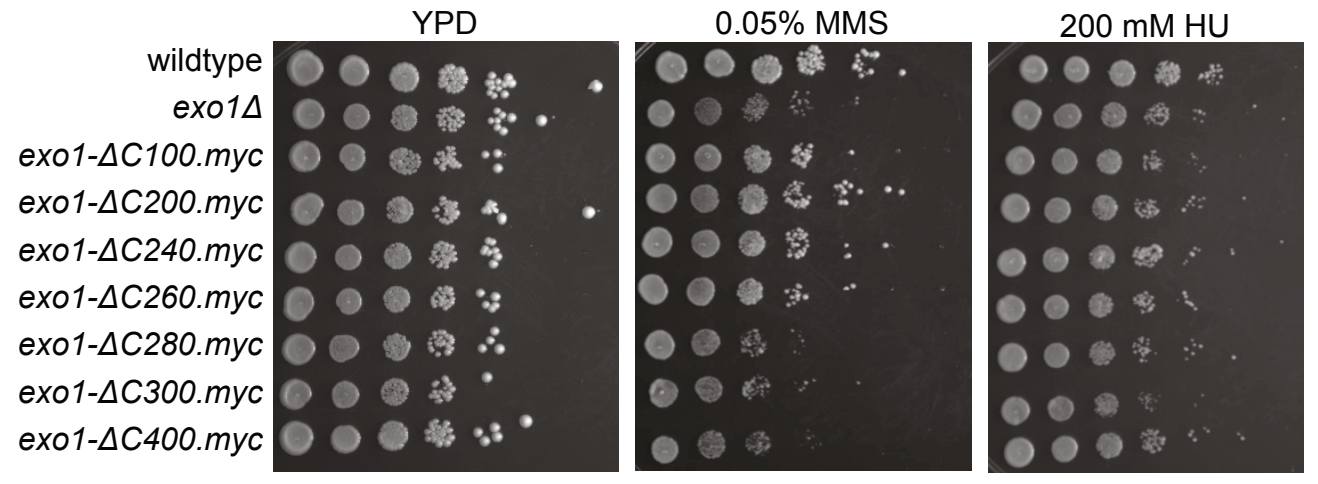

Figure 1 Expression of C-terminal truncations of Exo1 and sensitivity to DNA-damaging agents. (A) Intrinsic disorder prediction of Exo1 using the IUPred algorithm in which values above 0.5 indicate residues predicted to be intrinsically disordered and values below 0.5 to be ordered. The N-terminus, harboring conserved $\mathrm{N}$ - and I-nuclease domains, is predicted to be ordered, whereas the C-terminus, which appears devoid of enzymatic activity but contains phosphorylation sites and sites for interaction with mismatch repair proteins, is disordered. The sites at which the Exo1 truncations examined in this study terminate are indicted by vertical dotted lines. The location of conserved domains was adapted from reference [71]: nuclease domains (orange boxes, 16-96 aa, 123-257 aa), Mlh1 interaction domain (green box, 400-702 aa) and the Msh2 interaction domain (blue box, 368-702 aa). Phosphorylation sites at S372, S567, 5587 and S692, implicated in checkpoint regulation [74], are indicated by red asterisks. (B) Western blot analysis of expression of myc-epitope tagged exo1 truncations and wildtype Exo1. Molecular weight markers (kD) are indicated on the left. (C) Cells expressing Exo1 truncations lacking 280 or more C-terminal residues are as sensitive to $0.05 \%$ MMS as the exo1 1 mutant whereas cells expressing exo1 truncations lacking 260 or fewer C-terminal residues show wildtype levels of resistance to MMS. No sensitivity to $200 \mathrm{mM}$ hydroxyurea was observed for any of the tested yeast strains.

mutations in strains expressing the various C-terminal Exo1 truncations (Table 5). As in the GCR assay, deletion of up to 260 residues had no effect on the $\mathrm{Can}^{\mathrm{r}}$ mutation rate $(\mathrm{P}=0.3524)$ whereas deletion of 280 or more residues caused a null phenotype $(\mathrm{P}=0.0001)$.
Similarly, only deletion of 280 or more residues caused sensitivity to methyl methanesulfonate (MMS) (Figure $1 C)$. No sensitivity to $200 \mathrm{mM}$ hydroxyurea was observed for any of the exo1 mutants (Figure 1C). Thus, deletion of up to 260 residues caused a phenotype 
Table 4 Effect of exo1 mutations on the accumulation of GCRs in wildtype cells or cells lacking Sgs1 helicase.

\begin{tabular}{|c|c|c|}
\hline Relevant genotype & $\begin{array}{c}\text { GCR rate } \\
\left(\operatorname{Can}^{r} 5-\text { FOA }^{r} \times 10^{-10}\right)\end{array}$ & $\begin{array}{c}95 \% \mathrm{Cl}^{a} \\
\left(\operatorname{Can}^{\mathrm{r}} 5-\mathrm{FOA}^{\mathrm{r}} \times 10^{-10}\right)\end{array}$ \\
\hline $\operatorname{sgs} 1 \Delta$ & 89 & $57-177$ \\
\hline exol $1 \triangle$ & 24 & 7-79 \\
\hline exol $\triangle$ sgsi $1 \Delta$ & 40484 & $31076-49848$ \\
\hline EXO1.myc & 5 & $4.4-5.3$ \\
\hline exo1- $\Delta$ C100.myc & 5 & $4-6$ \\
\hline exo1- - C200.myc & $<4$ & $<3.8-4.8$ \\
\hline exo1- $\Delta C 260 . m y c$ & $<11$ & $<8-79$ \\
\hline exo1- $\triangle C 280 . m y c$ & $<11$ & $<8-29$ \\
\hline exo1- $\triangle$ C300.myc & $<18$ & $<5-70$ \\
\hline exo1- $\triangle$ C400.myc & 13 & $5-41$ \\
\hline sgsi $1 \triangle X O 1 . m y c$ & 78 & $29-118$ \\
\hline sgsi $1 \mathrm{exo1- \Delta C100.myc}$ & 125 & $80-186$ \\
\hline sgsi $\triangle$ exo 1- $\Delta$ C200.myc & 158 & $94-215$ \\
\hline sgs1 $\triangle$ exo 1- $\Delta$ C260.myc & 230 & $166-265$ \\
\hline sgs 1 $\triangle$ exo 1- $\Delta$ C280.myc & 26840 & $22925-34036$ \\
\hline sgs $1 \triangle$ exo1- $\Delta$ C300.myc & 31070 & $22871-33753$ \\
\hline sgs $1 \triangle$ exo1- $\Delta C 400 . m y c$ & 48190 & 39133-54471 \\
\hline
\end{tabular}

a $95 \%$ confidence intervals (Cl) for median GCR rates were calculated according to Nair [80].

similar to wildtype in all assays tested here, whereas deletion of 280 or more residues caused a null (exo1 $\Delta$ ) phenotype.

In addition to providing MMR protein interaction sites, the C-terminus of Exo1 contains four phosphorylation sites (S372, S567, S587, S692), which were recently shown to be important for the regulation of the DNA damage checkpoint in response to uncapped telomeres in a $c d c 13-1$ mutant [75]. Unlike in a $c d c 13-1$ mutant, we did not detect Exo1 phosphorylation in the sgs1 $1 \Delta$ mutant (data not shown), and deletion of the C-terminal third of Exo1 (exo1- $\triangle C 260$ ), which contains three of the four phosphorylation sites (S567, S587, S692), had no

Table 5 Effect of C-terminal deletions of Exo1 on the spontaneous mutation rate at the CAN1 locus.

\begin{tabular}{|c|c|c|c|}
\hline $\begin{array}{l}\text { Relevant } \\
\text { genotype }\end{array}$ & $\begin{array}{r}\text { CAN1 } \\
\left(\operatorname{Can}^{\mathrm{r}} \times 10^{-}\right. \\
7\end{array}$ & $\begin{array}{r}95 \% \mathrm{Cl}^{a} \\
\left(\operatorname{Can}^{\mathrm{r}} \times 10^{-}\right. \\
7\end{array}$ & $\begin{array}{r}\text { Increase over } \\
\text { wildtype }\end{array}$ \\
\hline wildtype & 3.27 & $2.50-5.82$ & 1 \\
\hline exo1 $1 \Delta$ & 11.47 & $\begin{array}{r}10.10- \\
28.52\end{array}$ & 3.5 \\
\hline exol- $\Delta$ C100.myc & 3.64 & $2.92-4.70$ & 1.1 \\
\hline exo1- $\Delta$ C200.myc & 5.31 & $3.90-5.90$ & 1.6 \\
\hline exo1- $\Delta$ C260.myc & 3.89 & $2.89-5.92$ & 1.2 \\
\hline exo1- $\Delta C 280 . m y c$ & 8.37 & $6.94-16.18$ & 2.6 \\
\hline exo1- $\triangle$ C300.myc & 10.72 & $8.55-19.88$ & 3.3 \\
\hline exo1- $\triangle$ C400.myc & 13.16 & $9.06-18.19$ & 4.0 \\
\hline
\end{tabular}

${ }^{a}$ 95\% confidence intervals $(\mathrm{Cl})$ for median $\mathrm{Can}^{r}$ rates were calculated according to Nair [80]. effect on Exo1 function in the assays used here $\left(\mathrm{Can}^{\mathrm{r}}\right.$ mutation rate, GCR assay, MMS sensitivity). The fourth phosphorylation site (S372) is present in both the exo1$\triangle C 260$ mutant and the exo1- $\triangle C 280$ mutant and, therefore, is not responsible for the different phenotypes associated with the two alleles. Thus, the known phosphorylation sites in Exo1 do not appear to be required for Exo1's role in mutation avoidance, resistance to MMS or suppression of GCRs in a sgs1 $1 \Delta$ mutant. Instead, it is likely that the $\triangle C 280$ deletion affects Exo1 nuclease activity directly by disrupting intramolecular interactions with the N-terminus. The loss of yet unknown posttranslational modifications in this segment of Exo1 or an indirect effect caused by the loss of interaction with other cellular factors could also lead to the deficiency of the exo1 $\triangle \mathrm{C} 280$ allele.

Besides the overall increase in genome instability, CAN1/LYP1/ALP1 rearrangements seen in the sgs1 $\triangle$ mec3 $\Delta$ mutant were also present in the sgs1 $\Delta$ mec3 $\Delta$ exo1 $1 \Delta$ mutant. Normally, Exo1 and Sgs1 function in independent end resection pathways that cooperate in the processing of DSBs, especially the long-range resection of the 5'-strand [19,20], and Marrero and Symington [21] recently showed that this extensive resection inhibits BIR in a plasmid-based assay. Besides upregulation of BIR, which was also accompanied by chromosome rearrangements, the exo1 $\Delta$ sgs $1 \Delta$ mutant was also more proficient in de novo telomere synthesis at $\mathrm{HO}$ endonuclease-induced chromosome breaks [18,21]. The combination of increased BIR and more efficient de novo telomere addition, both of which have been identified as major mechanisms for the healing of chromosome V breaks in the GCR assay [76,77], likely also explains the remarkably strong accumulation of genome rearrangements originating from spontaneous DNA lesions in the exo1 $\operatorname{sgs} 1 \Delta$ mutant studied here. Our study further adds that the exo1 $\Delta$ sgs $1 \Delta$ mutant has even greater potential for the accumulation of viable genome rearrangements, which is suppressed $(\sim 26$-fold $)$ in the sgs1 $1 \Delta$ exo1 $1 \Delta$ mutant by Mec3-dependent DNAdamage checkpoint functions $(\mathrm{P}<0.0001)$. Nonhomologous endjoining does not appear to be a significant source for these genome rearrangements, as indicated by the lack of any effect of LIG4 gene deletion in mutants with various combinations of $\operatorname{sgs} 1 \Delta$, exo $1 \Delta$ and mec3 $\Delta$ mutations (e.g., GCR rate of sgs $1 \Delta$ mec3 $\Delta$ exo $1 \Delta$

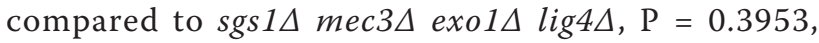
Table 3); however, it is also plausible that in the absence of one repair pathway DNA lesions simply become substrates for various other available repair pathways.

\section{Conclusion}

Our results indicate that spontaneous, interchromosomal translocations between short regions of sequence 
identity (5-41 bp), such as those present in the CAN1, LYP1 and ALP1 genes used in our assay, are promoted by Mec1/Dun1/Rad59-dependent pathways whereas Tel1, Mec3 and Sgs1 act as independent suppressors (Figure 2). The requirement for Pol32 and Rad1 in the translocation process further suggests the need for extensive DNA synthesis, such as seen in BIR, and the removal of nonhomologous overhangs from annealed single-strands, critical for SSA and implicated in GCR formation. Exo1 nuclease is a suppressor of overall genome rearrangements as well as CAN1/LYP1/ALP1 translocations when cells lack Sgs1 or both Sgs1 and Mec3. That the disordered, C-terminal third is dispensable for Exo1 function in our assays further indicates that physical interaction with MMR proteins in this region and regulation of Exo1 function in response to DNA-damage are not important for Exo1's role in the suppression of spontaneous GCRs, mutation avoidance and resistance to MMS.

\section{Methods}

\section{Yeast strains and media}

All strains used in this study are derived from KHSY802

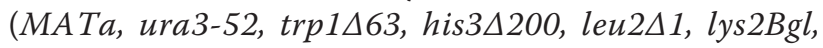
hom3-10, ade2A1, ade8, hxt13::URA3) or the isogenic strain of the opposite mating type. Desired gene deletions were introduced by HR-mediated integration of PCR products containing a selectable marker cassette flanked by 50 -nt sequences complementary to the target locus [78]. C-terminal truncations of Exo1 were

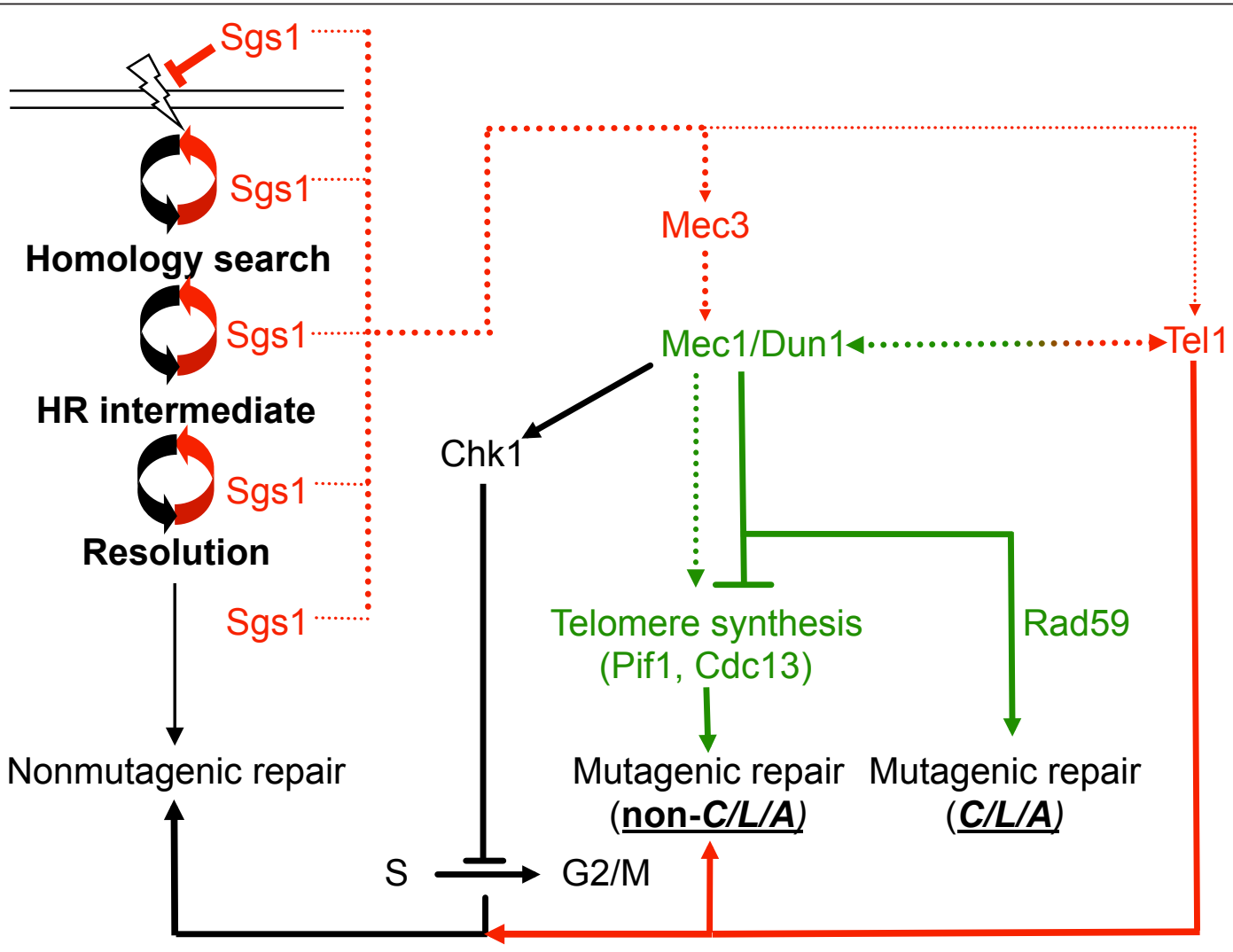

Figure 2 Factors affecting the suppression and promotion of chromosomal translocations between short segments of homology in CAN1, LYP1 and ALP1 in cells lacking Sgs1. In the absence of Sgs1, translocations between CAN1, LYP1 and ALP1 (referred to as C/L/A) are independently suppressed by the checkpoint components Mec3 and Tel1 (shown in red font), as suggested by the synergistic increases in the GCR rate and the C/L/A translocation rate of the sgsi $\triangle$ mutant upon deletion of MEC3 (sgsi $\triangle$ mec3 $\Delta$ ) and subsequently TEL1 (sgs $1 \triangle$ mec3 $\triangle$ tel1 $\Delta$ ). If Mec3 is absent (sgs1 $\triangle$ mec3A), C/L/A translocations form through a pathway that requires Mec1, Dun1 and homologous recombination (HR) factors (shown in green font), especially Rad52 and Rad59. Mec1 most likely promotes translocations by inhibiting de novo telomere additions by regulating Pif1 and $\mathrm{Cdc} 13$. In addition to mutagenic repair that leads to C/L/A translocations, other types of mutagenic repair (e.g., translocations between other genes, de novo telomere additions, deletions, insertions, inversions) and most likely also nonmutagenic repair products are

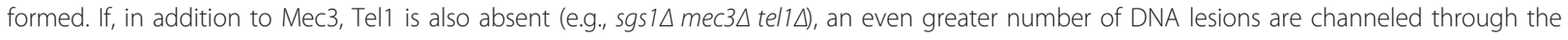
Mec1-dependent, C/L/A-promoting pathway. In contrast to dun1 $1 \Delta$, the chk1 $1 \Delta$ mutation does not lead to a significant GCR rate increase in the sgs $1 \Delta$ mec3 $\Delta$ mutant and does not inhibit $C / L / A$ translocation formation. Possibly, the inability to regulate cell cycle progression in the absence of Chk1 leads to increased formation of inviable GCRs. Dotted lines indicate events that occur in the absence of the protein from which the arrow originates; full lines indicate events that occur in the presence of the protein. 


\section{Table 6 Saccharomyces cerevisiae strains used in this study}

\begin{tabular}{|c|c|}
\hline Strain ID & Genotype \\
\hline KHSY802 & MATa, ura3-52, trp1 $\Delta 63$, his3 $\Delta 200$, leu2 $\Delta 1$, lys2Bgl, hom3-10, ade2 $\Delta 1$, ade8, hxt13::URA3 \\
\hline RDKY $3721^{a}$ & MATa, ura3-52, trp1 $\triangle 63$, his3 $\Delta 200$, leu2 $\Delta 1$, lys2Bgl, hom3-10, ade2 $\Delta 1$, ade8, hxt13::URA3, rad17::HIS3 \\
\hline $\begin{array}{l}\text { RDKY } 3739 \\
a\end{array}$ & MATa, ura3-52, trp1 $\triangle 63$, his3 200 , leu2 $\triangle 1$, lys2Bgl, hom3-10, ade2 $\triangle 1$, ade8, hxt13::URA3, dun1::HIS3 \\
\hline
\end{tabular}

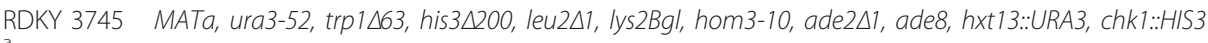

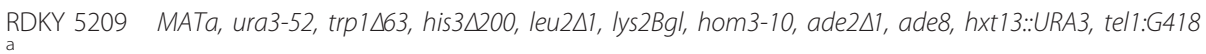

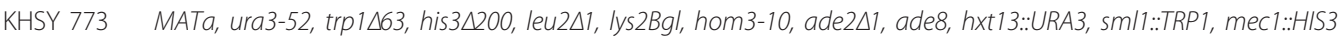

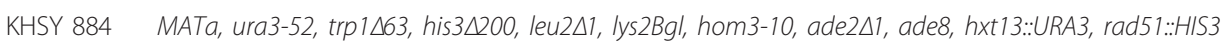

KHSY 906 MATa, ura3-52, trp1 $\triangle 63$, his3 $\triangle 200$, leu2 $\triangle 1$, lys2Bgl, hom3-10, ade2 11 , ade8, hxt13::URA3, mec3:.:HIS3

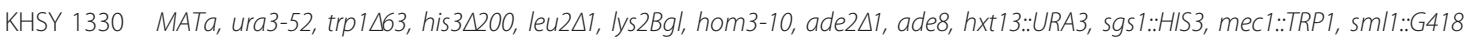

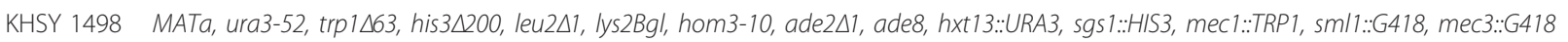

KHSY 1524 MATa, ura3-52, trp1 $\triangle 63$, his3 $\triangle 200$, leu2 $\Delta 1$, lys2Bgl, hom3-10, ade2 $\triangle 1$, ade8, hxt13::URA3, sgs 1::TRP1

KHSY 2260 MATa, ura3-52, trp1 $\triangle 63$, his3 200 , leu2 $\triangle 1$, lys2Bgl, hom3-10, ade2 $\triangle 1$, ade8, hxt13::URA3, sgs 1::TRP1, chk1::HIS3

KHSY 2265 MATa, ura3-52, trp1 $\triangle 63$, his3 $\triangle 200$, leu2 $\Delta 1$, lys2Bgl, hom3-10, ade2 $\Delta 1$, ade8, hxt13::URA3, sgs 1::TRP1, rad17::HIS3

KHSY 2280 MATa, ura3-52, trp1 $\triangle 63$, his3 $\triangle 200$, leu2 $\triangle 1$, lys2Bgl, hom3-10, ade2 $\triangle 1$, ade8, hxt13::URA3, sgs 1::TRP1, mec3::HIS3, rad59::G418

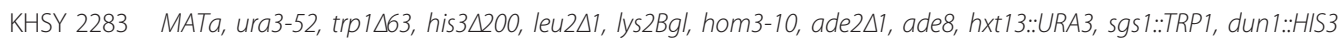

KHSY 2317 MATa, ura3-52, trp1 $\Delta 63$, his3 1200 , leu2 $\Delta 1$, lys2Bgl, hom3-10, ade2 1 1, ade8, hxt13::URA3, tel1::G418, mec3::HIS3

KHSY 2320 MATa, ura3-52, trp1 $\triangle 63$, his3 1200 , leu2 $\triangle 1$, lys2Bgl, hom3-10, ade2 $\triangle 1$, ade8, hxt13::URA3, sgs 1::TRP1, mec3::HIS3

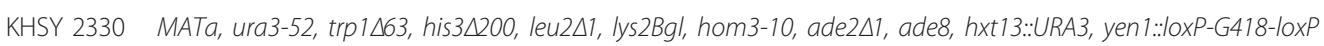

KHSY 2331 MATa, ura3-52, trp1 $\Delta 63$, his3 $\triangle 200$, leu2 $\Delta 1$, lys2Bgl, hom3-10, ade2 $\Delta 1$, ade8, hxt13::URA3, lig4:.IoxP-G418-loxP

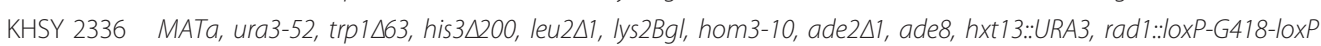

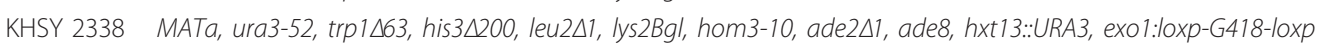

KHSY 2388 MATa, ura3-52, trp1 $\Delta 63$, his3 $\Delta 200$, leu2 $\Delta 1$, lys2Bgl, hom3-10, ade2 $\Delta 1$, ade8, hxt13::URA3, rad59::G418

KHSY 2402 MATa, ura3-52, trp1 $\Delta 63$, his3 $\triangle 200$, leu2 $\triangle 1$, lys2Bgl, hom3-10, ade2 11 , ade8, hxt13::URA3, sgs 1::TRP1, exo 1::IoxP-G418-loxP

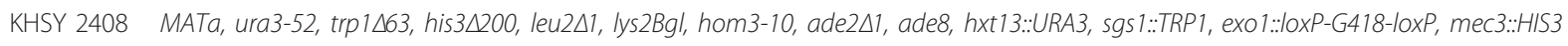

KHSY 2424 MATa, ura3-52, trp1 $\triangle 63$, his3 $\triangle 200$, leu2 11 , lys2Bgl, hom3-10, ade2 11 , ade8, hxt13::URA3, sgs 1::TRP1, rad1::10XP-G418-loxP

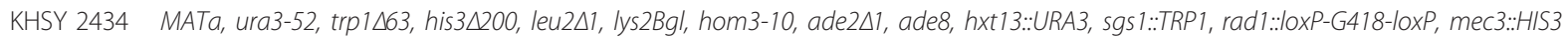

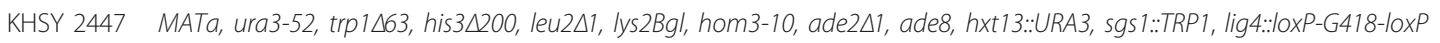

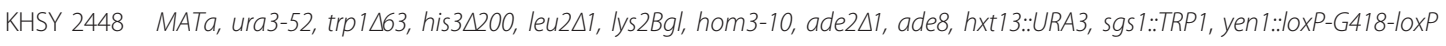

KHSY 2449 MATa, ura3-52, trp1 163 , his3 200 , leu2 $\triangle 1$, lys2Bgl, hom3-10, ade2A1, ade8, hxt13::URA3, sgs 1::TRP1, yen 1::IoxP-G418-loxP, mec3::HIS3

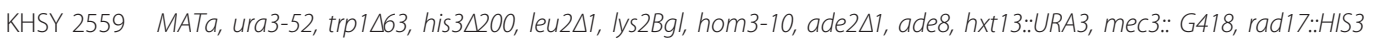

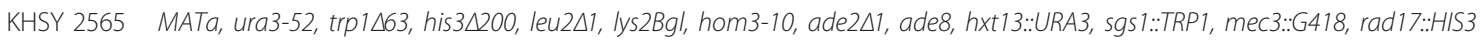

KHSY 2579 MATa, ura3-52, trp1 $\triangle 63$, his3 200 , leu2 $\triangle 1$, lys2Bgl, hom3-10, ade2 1 1, ade8, hxt13::URA3, sgs1:: TRP1, lig4:::G418, mec3::HIS3

KHSY 2585 MATa, ura3-52, trp1 $\triangle 63$, his3 2000 , leu2 $\triangle 1$, lys2Bgl, hom3-10, ade2 11 , ade8, hxt13::URA3, sgs1:::TRP1, tel1::G418, rad17::HIS3

KHSY 2588 MATa, ura3-52, trp1 $\triangle 63$, his3 1200 , leu2 $\triangle 1$, lys2Bgl, hom3-10, ade2 $\triangle 1$, ade8, hxt13::URA3, tel1::G418, rad17::HIS3

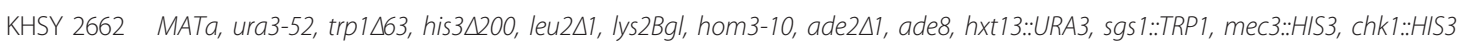

KHSY 2665 MATa, ura3-52, trp1 $\triangle 63$, his3 200 , leu2 $\triangle 1$, lys2Bgl, hom3-10, ade2 11 , ade8, hxt13::URA3, sgs 1::TRP1, mec3::HIS3, dun1::HIS3

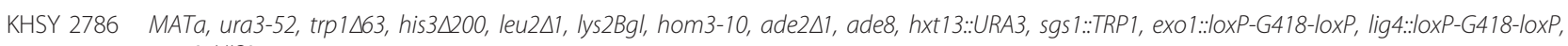
mec3::HIS3

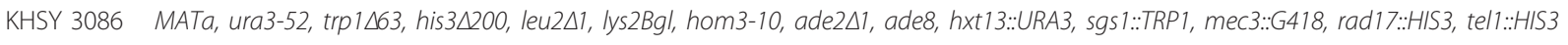

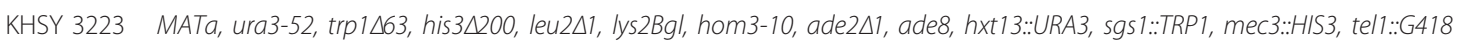

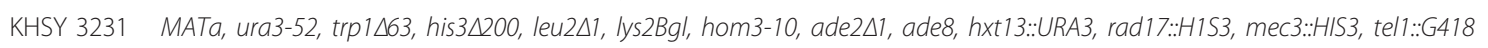

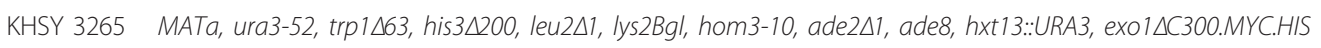

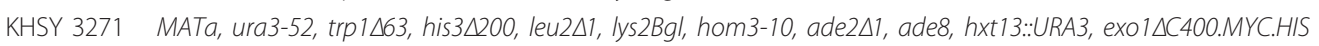

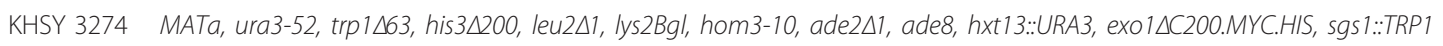

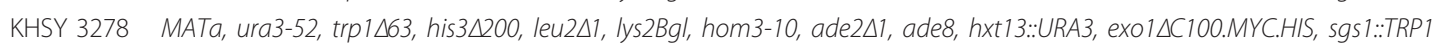

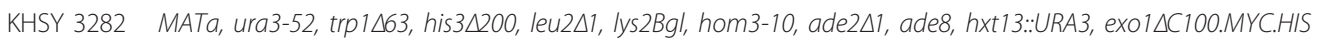

KHSY 3287 MATa, ura3-52, trp1 $\triangle 63$, his3 $\triangle 200$, leu2 $\triangle 1$, lys2Bgl, hom3-10, ade2 1 1, ade8, hxt13::URA3, EXO1.MYC.HIS, sgs1::TRP1

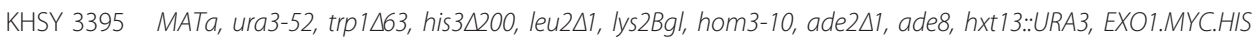

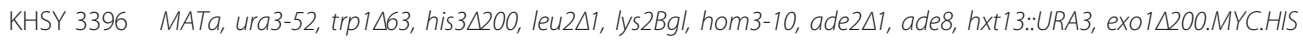


constructed by replacing the desired DNA sequence at the chromosomal EXO1 locus with a myc-epitope encoding sequence amplified from pFA-13Myc. His3MX6 (a gift from Mark Longtine, Washington University, St. Louis). Expression of Exo1 truncation alleles was confirmed by Western blotting using monoclonal anti-c-myc antibody (Covance). All haploid strains with multiple gene deletions were obtained by sporulating diploids heterozygous for the desired mutations to minimize the risk of obtaining suppressors. This was especially important for combinations of mutations known to cause fitness defects, such as sgs $1 \Delta$ and pol32 $\Delta$. Spore isolation was followed by genotyping of meiotic products by spotting on selective media or by PCR. All strains used in this study are listed in Table 6. Media for propagating yeast strains have been previously described [76,77].

\section{Sensitivity to DNA damaging agents HU and MMS}

Cell cultures were grown in yeast extract/peptone/dextrose $(Y P D)$ media and adjusted to OD600 $=1$. Tenfold dilutions were spotted on YPD, YPD supplemented with 0.05\% methyl-methanesulfonate (MMS) and YPD supplemented with $200 \mathrm{mM}$ hydroxyurea (HU). Colony growth was documented after incubation at $30^{\circ} \mathrm{C}$ for 3 days.

\section{Fluctuation Assays}

Rates of accumulating spontaneous gross-chromosomal rearrangements (GCRs) were determined by fluctuation analysis and the method of the median as previously described [77,79]. Cells with GCRs were detected by their resistance to canavanine and 5-fluoro-orotic acid $\left(\mathrm{Can}^{\mathrm{r}} 5\right.$-FOA $\left.{ }^{\mathrm{r}}\right)$ due to simultaneous inactivation of the CAN1 and URA3 genes, both located within a $12 \mathrm{~kb}$ nonessential region on the left arm of chromosome V. The median GCR rate is reported with $95 \%$ confidence intervals [80]. GCR clones were screened by PCR to identify clones with rearrangements between CAN1 on chromosome V and LYP1 and/or ALP1 (collectively referred to as $C A N 1 / L Y P 1 / A L P 1$ rearrangements in the text), located in opposite orientations on the same arm of chromosome XIV [10]. To determine the rate of accumulating spontaneous mutations that lead to inactivation of the CAN1 gene, 3-ml YPD cultures expressing wildtype Exo1 or C-terminal truncations of Exo1were grown overnight and aliquots were plated on synthetic media lacking arginine (US Biological) supplemented with $240 \mathrm{mg} \mathrm{ml}^{-1}$ canavanine (Sigma), and on YPD to obtain the viable cell count. Colonies were counted after two days of incubation at $30^{\circ} \mathrm{C}$. At least twelve independent cultures from three isolates were analyzed per yeast strain. The median $\operatorname{Can}^{\mathrm{r}}$ mutation rate is reported with $95 \%$ confidence intervals [80]. Statistical significance of differences in GCR rates was evaluated by using the Mann-Whitney test and programs from Dr. R. Lowry at Vassar College http://faculty.vassar.edu/lowry/ VassarStats.html.

\section{Protein extraction and Western blot analysis}

Cells were grown in YPD until they reached $\mathrm{OD}_{600}=$ 0.5. Whole cell extract was prepared from $5 \mathrm{ml}$ of culture using a standard trichloroacetic acid (TCA) extraction. Briefly, cells were pelleted, vortexed with glass beads for 10 minutes in $200 \mu \mathrm{l}$ of $20 \%$ TCA, followed by centrifugation for 2 minutes. The pellet was resuspended in sample buffer and $\mathrm{pH}$ was neutralized with $2 \mathrm{M}$ Tris buffer ( $\mathrm{pH}$ 7.6). Proteins were separated by PAGE, transferred to a PVDF membrane and incubated with monoclonal anti-c-myc antibody (Covance) to detect myc-tagged proteins. Bands were visualized using ECL Plus Chemiluminescence kit (GE Healthcare).

\section{List of abbreviations}

BIR: break-induced replication; Can ${ }^{\text {r: }}$ canavanine resistant; Cl: confidence interval; DSB: double-strand break; 5-FOA': 5-fluoro-orotic acid resistant; GCR: gross-chromosomal rearrangement; HR: homologous recombination; HU: hydroxyurea; MMR: mismatch repair; MMS: methyl methanesulfonate; SSA: single-strand annealing; TCA: trichloroacetic acid; YPD: yeast extract/ peptone/dextrose. 


\section{Acknowledgements}

We thank the members of the Schmidt lab and Gary Daughdrill (University of South Florida) for helpful discussions, Richard Kolodner (Ludwig Institute for Cancer Research, University of California San Diego) for sending strains and Mark Longtine (Washington University, St. Louis) for plasmids. This work was supported by National Institutes of Health grant 5R01GM081425 to KHS.

\section{Authors' contributions}

LD constructed yeast strains, performed experiments, analyzed data and performed statistical analyses. LH constructed yeast strains, performed experiments, analyzed data and performed statistical analyses. EV constructed yeast strains and performed experiments, KHS. designed the study, analyzed data and wrote the manuscript. All authors have read and approved the final manuscript.

\section{Competing interests}

The authors declare that they have no competing interests.

Received: 14 June 2011 Accepted: 31 October 2011

Published: 31 October 2011

\section{References}

1. Myung K, Chen C, Kolodner RD: Multiple pathways cooperate in the suppression of genome instability in Saccharomyces cerevisiae. Nature 2001, 411:1073-1076

2. Myung K, Datta A, Chen C, Kolodner RD: SGS1, the Saccharomyces cerevisiae homologue of BLM and WRN, suppresses genome instability and homeologous recombination. Nat Genet 2001, 27:113-116.

3. Myung K, Datta A, Kolodner RD: Suppression of spontaneous chromosomal rearrangements by $\mathrm{S}$ phase checkpoint functions in Saccharomyces cerevisiae. Cell 2001, 104:397-408.

4. Myung K, Kolodner RD: Suppression of genome instability by redundant S-phase checkpoint pathways in Saccharomyces cerevisiae. Proc Nat Acad Sci USA 2002, 99:4500-4507.

5. Myung K, Pennaneach V, Kats ES, Kolodner RD: Saccharomyces cerevisiae chromatin-assembly factors that act during DNA replication function in the maintenance of genome stability. Proc Natl Acad Sci USA 2003, 100:6640-6645

6. Putnam CD, Hayes TK, Kolodner RD: Specific pathways prevent duplication-mediated genome rearrangements. Nature 2009, 460:984-989.

7. Putnam CD, Jaehnig EJ, Kolodner RD: Perspectives on the DNA damage and replication checkpoint responses in Saccharomyces cerevisiae. DNA Repair (Amst) 2009, 8:974-982.

8. Putnam CD, Pennaneach V, Kolodner RD: Saccharomyces cerevisiae as a model system to define the chromosomal instability phenotype. Mol Cell Biol 2005, 25:7226-7238.

9. Schmidt KH, Kolodner RD: Suppression of spontaneous genome rearrangements in yeast DNA helicase mutants. Proc Natl Acad Sci USA 2006, 103:18196-18201.

10. Schmidt KH, Wu J, Kolodner RD: Control of Translocations between Highly Diverged Genes by Sgs1, the Saccharomyces cerevisiae Homolog of the Bloom's Syndrome Protein. Mol Cell Biol 2006, 26:5406-5420.

11. Antoccia A, Kobayashi J, Tauchi H, Matsuura S, Komatsu K: Nijmegen breakage syndrome and functions of the responsible protein, NBS1. Genome Dyn 2006, 1:191-205.

12. Carney JP, Maser RS, Olivares H, Davis EM, Le Beau M, Yates JR, Hays L, Morgan WF, Petrini JH: The hMre11/hRad50 protein complex and Nijmegen breakage syndrome: linkage of double-strand break repair to the cellular DNA damage response. Cell 1998, 93:477-486.

13. Varon R, Vissinga C, Platzer M, Cerosaletti KM, Chrzanowska KH, Saar K, Beckmann G, Seemanova E, Cooper PR, Nowak NJ, et al: Nibrin, a novel DNA double-strand break repair protein, is mutated in Nijmegen breakage syndrome. Cell 1998, 93:467-476.

14. Ellis NA, Groden J, Ye TZ, Straughen J, Lennon DJ, Ciocci S, Proytcheva M, German J: The Bloom's syndrome gene product is homologous to RecQ helicases. Cell 1995, 83:655-666.

15. Yu CE, Oshima J, Fu YH, Wijsman EM, Hisama F, Alisch R, Matthews S, Nakura J, Miki T, Ouais S, et al: Positional cloning of the Werner's syndrome gene. Science 1996, 272:258-262.
16. Savitsky K, Bar-Shira A, Gilad S, Rotman G, Ziv Y, Vanagaite L, Tagle DA, Smith S, Uziel T, Sfez S, et al: A single ataxia telangiectasia gene with a product similar to PI-3 kinase. Science 1995, 268:1749-1753.

17. Morrow DM, Tagle DA, Shiloh Y, Collins FS, Hieter P: TEL1, an S. cerevisiae homolog of the human gene mutated in ataxia telangiectasia, is functionally related to the yeast checkpoint gene MEC1. Cell 1995, 82:831-840.

18. Lydeard JR, Lipkin-Moore Z, Jain S, Eapen W, Haber JE: Sgs1 and exo1 redundantly inhibit break-induced replication and de novo telomere addition at broken chromosome ends. PLoS Genet 2010, 6:e1000973.

19. Mimitou EP, Symington LS: Sae2, Exo1 and Sgs1 collaborate in DNA double-strand break processing. Nature 2008, 455:770-774

20. Zhu Z, Chung WH, Shim EY, Lee SE, Ira G: Sgs1 helicase and two nucleases Dna2 and Exo1 resect DNA double-strand break ends. Cell 2008, 134:981-994.

21. Marrero VA, Symington LS: Extensive DNA end processing by exo1 and sgs1 inhibits break-induced replication. PLoS Genet 2010, 6:e1001007.

22. Cobb JA, Bjergbaek L, Gasser SM: RecQ helicases: at the heart of genetic stability. FEBS Lett 2002, 529:43-48.

23. Frei C, Gasser SM: The yeast Sgs $1 p$ helicase acts upstream of Rad53p in the DNA replication checkpoint and colocalizes with Rad53p in S-phasespecific foci. Genes Dev 2000, 14:81-96.

24. Ira G, Malkova A, Liberi G, Foiani M, Haber JE: Srs2 and Sgs1-Top3 suppress crossovers during double-strand break repair in yeast. Cell 2003, 115:401-411

25. Lee SK, Johnson RE, Yu SL, Prakash L, Prakash S: Requirement of yeast SGS1 and SRS2 genes for replication and transcription. Science 1999, 286:2339-2342.

26. Versini G, Comet I, Wu M, Hoopes L, Schwob E, Pasero P: The yeast Sgs1 helicase is differentially required for genomic and ribosomal DNA replication. Embo J 2003, 22:1939-1949.

27. Bentley NJ, Holtzman DA, Flaggs G, Keegan KS, DeMaggio A, Ford JC, Hoekstra M, Carr AM: The Schizosaccharomyces pombe rad3 checkpoint gene. Embo J 1996, 15:6641-6651.

28. Carr AM: Control of cell cycle arrest by the Mec1sc/Rad3sp DNA structure checkpoint pathway. Curr Opin Genet Dev 1997, 7:93-98.

29. Cimprich KA, Shin TB, Keith CT, Schreiber SL: cDNA cloning and gene mapping of a candidate human cell cycle checkpoint protein. Proc Natl Acad Sci USA 1996, 93:2850-2855.

30. Weinert TA, Kiser GL, Hartwell LH: Mitotic checkpoint genes in budding yeast and the dependence of mitosis on DNA replication and repair. Genes Dev 1994, 8:652-665.

31. Tercero JA, Diffley JF: Regulation of DNA replication fork progression through damaged DNA by the Mec1/Rad53 checkpoint. Nature 2001, 412:553-557.

32. Merrill BJ, Holm C: A requirement for recombinational repair in Saccharomyces cerevisiae is caused by DNA replication defects of mec1 mutants. Genetics 1999, 153:595-605.

33. Grushcow JM, Holzen TM, Park KJ, Weinert T, Lichten M, Bishop DK: Saccharomyces cerevisiae checkpoint genes MEC1, RAD17 and RAD24 are required for normal meiotic recombination partner choice. Genetics 1999, 153:607-620.

34. Kato R, Ogawa H: An essential gene, ESR1, is required for mitotic cell growth, DNA repair and meiotic recombination in Saccharomyces cerevisiae. Nucleic Acids Res 1994, 22:3104-3112.

35. Lydall D, Nikolsky $Y$, Bishop DK, Weinert T: A meiotic recombination checkpoint controlled by mitotic checkpoint genes. Nature 1996, 383:840-843.

36. Greenwell PW, Kronmal SL, Porter SE, Gassenhuber J, Obermaier B, Petes TD: TEL1, a gene involved in controlling telomere length in $S$. cerevisiae, is homologous to the human ataxia telangiectasia gene. Cell 1995, 82:823-829.

37. Ritchie KB, Mallory JC, Petes TD: Interactions of TLC1 (which encodes the RNA subunit of telomerase), TEL1, and MEC1 in regulating telomere length in the yeast Saccharomyces cerevisiae. Mol Cell Biol 1999, 19:6065-6075.

38. Sanchez Y, Desany BA, Jones WJ, Liu Q, Wang B, Elledge SJ: Regulation of RAD53 by the ATM-like kinases MEC1 and TEL1 in yeast cell cycle checkpoint pathways. Science 1996, 271:357-360. 
39. Melo JA, Cohen J, Toczyski DP: Two checkpoint complexes are independently recruited to sites of DNA damage in vivo. Genes Dev 2001, 15:2809-2821

40. Kondo T, Wakayama T, Naiki T, Matsumoto K, Sugimoto K: Recruitment of Mec1 and Ddc1 checkpoint proteins to double-strand breaks through distinct mechanisms. Science 2001, 294:867-870

41. Makovets $\mathrm{S}$, Blackburn EH: DNA damage signalling prevents deleterious telomere addition at DNA breaks. Nat Cell Biol 2009, 11:1383-1386.

42. Zhang W, Durocher D: De novo telomere formation is suppressed by the Mec1-dependent inhibition of Cdc13 accumulation at DNA breaks. Genes Dev 24:502-515.

43. Bashkirov VI, King JS, Bashkirova EV, Schmuckli-Maurer J, Heyer WD: DNA repair protein Rad55 is a terminal substrate of the DNA damage checkpoints. Mol Cell Biol 2000, 20:4393-4404

44. Flott S, Alabert C, Toh GW, Toth R, Sugawara N, Campbell DG, Haber JE, Pasero P, Rouse J: Phosphorylation of SIx4 by Mec1 and Tel1 regulates the single-strand annealing mode of DNA repair in budding yeast. $\mathrm{Mol}$ Cell Biol 2007, 27:6433-6445.

45. Ehmsen KT, Heyer WD: Saccharomyces cerevisiae Mus81-Mms4 is a catalytic, DNA structure-selective endonuclease. Nucleic Acids Res 2008, 36:2182-2195

46. Mordes DA, Nam EA, Cortez D: Dpb11 activates the Mec1-Ddc2 complex. Proc Natl Acad Sci USA 2008, 105:18730-18734.

47. Herzberg K, Bashkirov VI, Rolfsmeier M, Haghnazari E, McDonald WH, Anderson S, Bashkirova EV, Yates JR, Heyer WD: Phosphorylation of Rad55 on serines 2,8 , and 14 is required for efficient homologous recombination in the recovery of stalled replication forks. Mol Cell Biol 2006, 26:8396-8409.

48. Zhou Z, Elledge SJ: DUN1 encodes a protein kinase that controls the DNA damage response in yeast. Cell 1993, 75:1119-1127.

49. Huang M, Zhou Z, Elledge SJ: The DNA replication and damage checkpoint pathways induce transcription by inhibition of the Crt1 repressor. Cell 1998, 94:595-605.

50. Sanchez Y, Bachant J, Wang H, Hu F, Liu D, Tetzlaff M, Elledge SJ: Control of the DNA damage checkpoint by chk1 and rad53 protein kinases through distinct mechanisms. Science 1999, 286:1166-1171.

51. Gardner R, Putnam CW, Weinert T: RAD53, DUN1 and PDS1 define two parallel G2/M checkpoint pathways in budding yeast. Embo J 1999, 18:3173-3185

52. Chan JE, Kolodner RD: A genetic and structural study of genome rearrangements mediated by high copy repeat Ty1 elements. PLoS Genet 7:e1002089.

53. Chen $Q$, ljpma A, Greider CW: Two survivor pathways that allow growth in the absence of telomerase are generated by distinct telomere recombination events. Mol Cell Biol 2001, 21:1819-1827.

54. Teng SC, Chang J, McCowan B, Zakian VA: Telomerase-independent lengthening of yeast telomeres occurs by an abrupt Rad50p-dependent, Rif-inhibited recombinational process. Mol Cell 2000, 6:947-952.

55. Teng SC, Zakian VA: Telomere-telomere recombination is an efficient bypass pathway for telomere maintenance in Saccharomyces cerevisiae. Mol Cell Biol 1999, 19:8083-8093.

56. Malkova A, Ivanov EL, Haber JE: Double-strand break repair in the absence of RAD51 in yeast: a possible role for break-induced DNA replication. Proc Natl Acad Sci USA 1996, 93:7131-7136.

57. Signon L, Malkova A, Naylor ML, Klein H, Haber JE: Genetic requirements for RAD51- and RAD54-independent break-induced replication repair of a chromosomal double-strand break. Mol Cell Biol 2001, 21:2048-2056.

58. Symington LS: Role of RAD52 epistasis group genes in homologous recombination and double-strand break repair. Microbiol Mol Biol Rev 2002, 66:630-670, table of contents.

59. Sugawara N, Ira G, Haber JE: DNA length dependence of the single-strand annealing pathway and the role of Saccharomyces cerevisiae RAD59 in double-strand break repair. Mol Cell Biol 2000, 20:5300-5309.

60. Schmidt KH, Viebranz E, Doerfler L, Lester C, Rubenstein A: Formation of complex and unstable chromosomal translocations in yeast. PLOS One 2010, 5:e12007.

61. Pannunzio NR, Manthey GM, Bailis AM: RAD59 is required for efficient repair of simultaneous double-strand breaks resulting in translocations in Saccharomyces cerevisiae. DNA Repair (Amst) 2008, 7:788-800.

62. Onoda F, Seki M, Miyajima A, Enomoto T: Elevation of sister chromatid exchange in Saccharomyces cerevisiae sgs 1 disruptants and the relevance of the disruptants as a system to evaluate mutations in Bloom's syndrome gene. Mutat Res 2000, 459:203-209.

63. Ooi SL, Shoemaker DD, Boeke JD: DNA helicase gene interaction network defined using synthetic lethality analyzed by microarray. Nat Genet 2003, 35:277-286.

64. Watt PM, Hickson ID, Borts RH, Louis EJ: SGS1, a homologue of the Bloom's and Werner's syndrome genes, is required for maintenance of genome stability in Saccharomyces cerevisiae. Genetics 1996, 144:935-945.

65. Louis EJ, Haber JE: The structure and evolution of subtelomeric $Y^{\prime}$ repeats in Saccharomyces cerevisiae. Genetics 1992, 131:559-574.

66. Lydeard JR, Jain S, Yamaguchi M, Haber JE: Break-induced replication and telomerase-independent telomere maintenance require Pol32. Nature 2007, 448:820-823.

67. Fishman-Lobell J, Haber JE: Removal of nonhomologous DNA ends in double-strand break recombination: the role of the yeast ultraviolet repair gene RAD1. Science 1992, 258:480-484.

68. Ivanov EL, Haber JE: RAD1 and RAD10, but not other excision repair genes, are required for double-strand break-induced recombination in Saccharomyces cerevisiae. Mol Cell Biol 1995, 15:2245-2251.

69. Hwang JY, Smith S, Myung K: The Rad1-Rad10 complex promotes the production of gross chromosomal rearrangements from spontaneous DNA damage in Saccharomyces cerevisiae. Genetics 2005, 169:1927-1937.

70. Bartsch S, Kang LE, Symington LS: RAD51 is required for the repair of plasmid double-stranded DNA gaps from either plasmid or chromosomal templates. Mol Cell Biol 2000, 20:1194-1205.

71. Malagon F, Aguilera A: Yeast spt6-140 mutation, affecting chromatin and transcription, preferentially increases recombination in which Rad51pmediated strand exchange is dispensable. Genetics 2001, 158:597-611.

72. Tran PT, Erdeniz N, Symington LS, Liskay RM: EXO1-A multi-tasking eukaryotic nuclease. DNA Repair (Amst) 2004, 3:1549-1559.

73. Schmutte C, Sadoff MM, Shim KS, Acharya S, Fishel R: The interaction of DNA mismatch repair proteins with human exonuclease I. J Biol Chem 2001, 276:33011-33018.

74. Tishkoff DX, Boerger AL, Bertrand P, Filosi N, Gaida GM, Kane MF, Kolodner RD: Identification and characterization of Saccharomyces cerevisiae EXO1, a gene encoding an exonuclease that interacts with MSH2. Proc Natl Acad Sci USA 1997, 94:7487-7492.

75. Morin I, Ngo HP, Greenall A, Zubko MK, Morrice N, Lydall D: Checkpointdependent phosphorylation of Exo1 modulates the DNA damage response. Embo J 2008, 27:2400-2410.

76. Chen C, Umezu K, Kolodner RD: Chromosomal rearrangements occur in S. cerevisiae $\mathrm{rfa} 1$ mutator mutants due to mutagenic lesions processed by double-strand-break repair. Mol Cell 1998, 2:9-22.

77. Schmidt KH, Pennaneach V, Putnam CD, Kolodner RD: Analysis of gross chromosomal rearrangements in Saccharomyces cerevisiae. Methods Enzymol 2006, 409:462-476.

78. Gietz RD, Woods RA: Yeast transformation by the LiAc/SS Carrier DNA/ PEG method. Methods Mol Biol 2006, 313:107-120.

79. Lea DE, Coulson CA: The distribution of the number of mutants in bacterial populations. J Genet 1949, 49:264-285.

80. Nair KR: Table of confidence intervals for the median in samples from any continuous population. Sankhya 1940, 4:551-558.

81. Mirzaei H, Syed S, Kennedy J, Schmidt KH: Sgs1 truncations inducegenome rearrangements but suppress detrimental effects of BLM overexpression in Saccharomyces cerevisiae. J Mol Biol 2011, 405:877-891.

82. Schmidt KH, Viebranz EB, Harris LB, Mirzaei-Souderjani H, Syed S, Medicus R: Defects in DNA lesion bypass lead to spontaneous chromosomal rearrangements and increased cell death. Eukaryot Cell 2010, 9:315-324

doi:10.1186/2041-9414-2-8

Cite this article as: Doerfler et al:: Differential genetic interactions between Sgs1, DNA-damage checkpoint components and DNA repair factors in the maintenance of chromosome stability. Genome Integrity $20112: 8$. 